\title{
Organic geochemistry of suspended and settling particulate matter in Lake Michigan
}

\author{
P. A. Meyers, ${ }^{\prime}$ M. J. Leenheer, ${ }^{1 *}$ B. J. EAdie, ${ }^{2}$ and S. J. MAULe' \\ 'Oceanography Program, Department of Atmospheric and Oceanic Science, \\ The University of Michigan, Ann Arbor, Michigan 48109 \\ ${ }^{2}$ Great Lakes Environmental Research Laboratory. National Oceanic and Atmospheric Administration. \\ 2300 Washtenaw Avenue. Ann Arbor. Michigan 48103
}

(Received January 12, 1983; accepted in revised form November 30, 1983)

\begin{abstract}
Organic matter contained in particulate matter in Lake Michigan waters and sediments has been characterized by $\mathrm{C} / \mathrm{N}$ ratios and by distributions of biomarker fatty acids, alkanols, sterols, and aliphatic hydrocarbons. Differences in organic constituents of particulate matter from various depths and distances from shore indicate a complex interaction of production, transformation, and destruction of the organic matter contained in sinking particles. Near-surface material contains important contributions of landderived organic matter, presumably of eolian input. Midwater particles have predominantly aquatic organic material of algal origin. At the sediment-water interface, selective suspension of the finer fractions of surficial sediments enriches bottom nepheloid layers with these sediment size classes. As a result. near-bottom particulate matter has an aquatic biomarker character. Organic matter associated with sinking particles undergoes substantial degradation during passage to the bottom of Lake Michigan. and aquatic components are selectively destroyed relative to terrigenous components.
\end{abstract}

\section{INTRODUCTION}

THE PRODUCTION and destruction of organic matter within natural bodies of water are dynamic processes related to a number of environmental factors-availability of sunlight and dissolved nutrients, water temperature and mixing, and the composition of aquatic biological communities as examples. In general, most of the organic matter present in the upper waters of lakes and oceans originates from aquatic biota; yet. only a small percentage of this material escapes remineralization during sinking (KNAUER and MARTIN, 1981; SUESS, 1980; WAKEHAM et al., 1980; DEAN, 1981; LORENZEN et al. 1983) and is incorporated in sediments. Moreover, organic materials transported to lakes and oceans from anthropogenic and biological sources on land may behave differently than those of aquatic origins ( $f$. PRAHL et al., 1980). Selective alteration and destruction of organic matter components within the water column influence the ultimate character of sedimentary organic content and affect the cycling of organic carbon in aquatic systems.

Recent investigations show the importance and complexity of changes affecting particulate organic matter as it sinks to the bottom of oceanic and lacustrine areas. Preferential removal of nitrogenous and phosphorus-containing organic compounds occurs during remineralization of organic matter in the upper water column (SUESS and MÜLLER, 1980). In addition, the small fraction of the original biomass which reaches the sediment-water interface is subject to benthic reworking and renewed degradation prior to permanent burial in the sediments (COBLER and DYMOND, 1980;

* Present address: Cities Service Technology Center, P.O. Box 3908, Tulsa, Oklahoma 74102.
Suess and Müller, 1980; PraHL et al., 1980). Important factors enhancing preservation of sinking organic matter are its incorporation into the fecal pellets of grazing zooplankton (PRAHL and CARPENTER, 1979; SUESS, 1980) and its sorption by clay minerals (SUESS and MÜLLER, 1980). Such factors speed the transport of degradable compounds from surface waters to the bottom and may decrease their susceptibility to microbial attack.

Specific indicators of sources of organic matter and of its alteration have been used to investigate the fate of organic matter during its transit to bottom sediments. GAGOSIAN (1976) presents a detailed profile of sterols extracted from water collected at different depths in the Sargasso Sea, and he describes evidence of substantial degradation of some compounds during their sinking. CRISP et al. (1979) employ a number of molecular, elemental, and isotopic biomarkers to distinguish aquatic, terrigenous, and anthropogenic inputs of particulate organic matter to sediment traps at four locations offshore of southern California. PRAHL t al. (1980) show that aquatic organic matter is preferentially remineralized during sinking and at the sedimentwater boundary in Dabob Bay, Washington, and, hence, terrigenous biomarkers dominate sediments of this coastal marine location. WAKEHAM and coworkers (1980, 1982) report preferential losses of lipid components compared to the total organic content of settling particles trapped at four depths in the equatorial Atlantic Ocean.

The results of our earlier study of fatty acid and hydrocarbon compositions of sediment trap material from Lake Michigan (MEYERS et al, 1980) suggest a complex interaction of different organic inputs, alteration and remineralization processes, as well as nearbottom sediment resuspension. We have expanded our 
previous investigation to include more indicators of sources and of degradation, and to compare suspended matter from different water depths and sampling locations. This report describes the results of our further study and interprets them in terms of the fate of organic matter in a large lake.

\section{METHODS}

\section{Sampling}

Sediment traps consisting of $50 \mathrm{~cm} \times 10 \mathrm{~cm}$ Plexiglas cylinders attached to $500 \mathrm{ml}$ polyethylene bottles were positioned at the bottom of the metalimnion (31 to $35 \mathrm{~m}$ ) and $\mathrm{l} \mathrm{m}$ above the lake bottom at three sites in Lake Michigan from early June through mid-September, 1978; the water depths of the near-bottom traps were $40 \mathrm{~m} .86 \mathrm{~m}$, and 100 $m$ at Stations 6, 7, and 8 respectively. Mercuric chloride was used to retard organic matter losses in sediment trap contents. Information about sediment trap deployment and efficiencies is given by CHAMBERS and EADIE (1981). Portions of trap contents for organic matter study were freeze-dried prior to analysis.

Samples of suspended particulate matter were collected in July, 1980 , from $1 \mathrm{~m}$ below the water surface. Water samples were filtered through glass fiber filters having a nominal retention size of $1 \mu \mathrm{m}$. Figure 1 shows the locations of the sediment trap sites in relation to suspended particulate matter stations which consisted of one station within the plume of the Grand River (GRP), one nearshore station close to but not within this turbid plume (NS), and one open-lake location $25 \mathrm{~km}$ offshore $(\mathrm{OL})$. Particulate matter samples were $\mathrm{im}$. mediately frozen after filtering and remained stored at $-20^{\circ} \mathrm{C}$ until analysis.

To relate the organic contents of suspended particulate matter and of settling trap material to that of Lake Michigan sediment, a Ponar grab sample was obtained at Station 8 (Fig. 1). This sample, representing the top $10 \mathrm{~cm}$ of lake sediment, was collected in July 1980 and kept frozen until analysis. It was freeze-dried prior to extraction.

\section{Analysis}

A two-stage extraction procedure was used on all suspended matter, sediment traps, and sediment samples. Soxhlet extraction with toluene/methanol yielded the easily extracted fraction of organic materials, hereafter denoted as "unbound" A second extraction with $1.5 \mathrm{~N} \mathrm{KOH}$ in methanot/toluen provided the hydrolyzable, "bound" fraction of organic com ponents. Both fractions were treated with methanolic boron trifluoride to convert fatty acids to their methyl esters. and then lipid subfractions were separated by column chromatography on silica gel. The fractions so obtained contained alkanes and alkenes. aromatic hydrocarbons. fatty acid methyl esters, and hydroxy lipids, including sterols and alkanols. $\mathrm{Hy}$ droxy compounds were silylated with BSTFA prior to analysis

Splitiess injection gas-liquid chromatography was employed to determine the types and amounts of compounds presen: in the lipid subfractions. A Hewlett-Packard 5830 FID gas chromatograph equipped with either a $10 \mathrm{~m}$ SP2 100 or a 10 m SE54 glass capillary column was used with hydrogein as carrier gas. Quantification was accomplished through the use of known amounts of internal standards added to each un. bound and bound sample prior to its alkaline hydrolvsis, Individual compounds were identified by retention times and by GC-MS analysis of representative samples with a Finnigan 1015 mass spectrometer interfaced with a Varian 1400 gas chromatograph. LEENHEER (1981) provides full details of the analytical methods and describes the development of the procedures used in this study.

\section{RESULTS AND DISCUSSION}

\section{General observations}

Results of organic matter analyses of the sediment trap contents are summarized in Table 1 . In most cases, concentrations of the unbound material released by Soxhlet extraction exceed those of the corresponding bound fraction. The only exceptions occur in the hy drocarbon fractions from the shallower traps at Stations 6 and 7. Generally, fatty acid, alkanol, and sterol frac: tions show higher concentrations of unbound contents relative to bound in the shallower traps than in the near-bottom ones; but, for the alcohols, the ratio is less than that found for the fatty acids, and is less consistent. Hydrocarbon concentrations, in contrast, have lower unbound-to-bound ratios in the contents of shallower traps than in the deep ones.

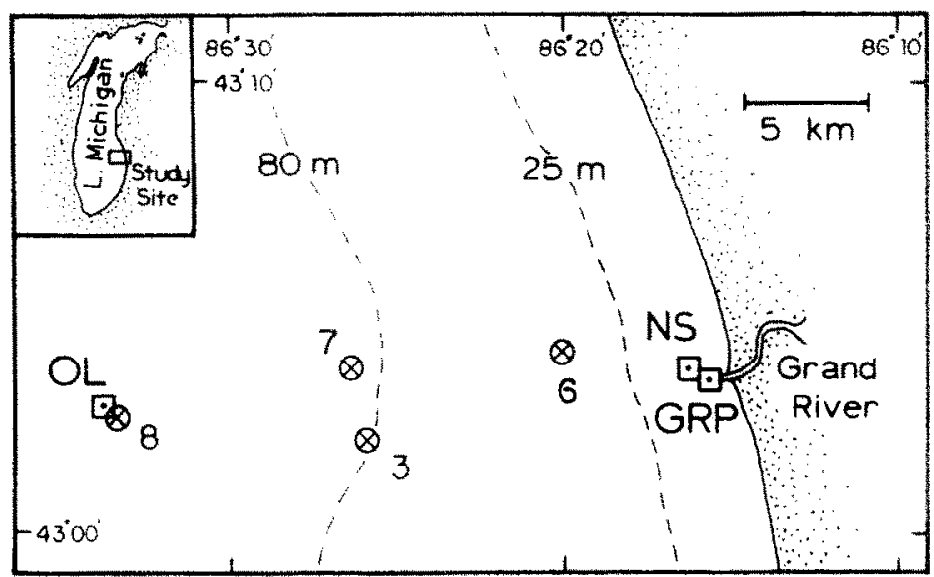

FIG. 1. Sampling locations in Lake Michigan. Sediment traps were positioned at Stations 3,6. 7 , and i from June 6 to September 15, 1978. Data from Station 3 are described by MEYERS et al (1980). Surficial sediments were collected by Ponar grab at Station 8 in July 1980 . Suspended particulate material was filtered from water samples collected in July 1980 at a water depth of $1 \mathrm{~m}$ in the Grand River plume (GRP) and at nearshore (NS) and open-lake (OL) locations. 
Table 1: Concentrations of total organic carbon (TOC), total extractable lipid fractions, and ratios of selected aquatic/terrigenous indicators in setting material collected by sediment traps at stations in Lake Michigan shown in Figure 1. High hydrocarbon concentrations in aterial from $35 \mathrm{~m}$ traps include both resolved components and unresolved complex mixture components.

\begin{tabular}{|c|c|c|c|c|c|c|}
\hline \multirow{2}{*}{$\begin{array}{l}\text { Organic Matter } \\
\text { Component }\end{array}$} & \multicolumn{6}{|c|}{ Station-Depth (n) } \\
\hline & $6-31$ & $6-40$ & $7-35$ & $7-86$ & $8-35$ & $8-100$ \\
\hline \multicolumn{7}{|l|}{ Organic Carbon } \\
\hline Concentration $(\mathrm{mg} / \mathrm{g})$ & 130 & 39 & 221 & 34 & 546 & 41 \\
\hline C/N ratio & 9.6 & 7.7 & 9.9 & 7.2 & 8.7 & 8.5 \\
\hline \multicolumn{7}{|l|}{ Fatty Acids } \\
\hline \multirow{2}{*}{\multicolumn{7}{|c|}{$\begin{array}{l}\text { Concentration }(\mathrm{Hg} / \mathrm{g}) \\
\text { unbound }\end{array}$}} \\
\hline & 8060 & 984 & 22100 & 741 & 49400 & 1370 \\
\hline bound & 70 & 119 & 265 & 105 & 385 & 234 \\
\hline \multicolumn{7}{|l|}{$\mathrm{n}-\mathrm{Cl6} / \mathrm{n}-\mathrm{C} 26$ ratio } \\
\hline $\begin{array}{l}\text { unbound } \\
\text { bound }\end{array}$ & $>100$ & 22 & $>100$ & 23 & $>100$ & 36 \\
\hline bound & $>100$ & & $>100$ & 30 & $>100$ & 100 \\
\hline \multicolumn{7}{|l|}{ Hydrocarbons } \\
\hline \multicolumn{7}{|l|}{ Concentration $(\mu \mathrm{g} / \mathrm{g})$} \\
\hline $\begin{array}{l}\text { unbound } \\
\text { bound }\end{array}$ & 91 & 63 & $\begin{array}{r}7450 \\
10300\end{array}$ & $\begin{array}{r}34 \\
2\end{array}$ & 11900 & 27 \\
\hline \multicolumn{7}{|l|}{$\mathrm{n}-\mathrm{C} 1.7 / \mathrm{n}-\mathrm{C} 29$ ratio } \\
\hline unbotind & 1.3 & 8.3 & 1.8 & 6.7 & 1.3 & 5.3 \\
\hline bound & 6.3 & 2.1 & 10 & 2.0 & 25 & 1.4 \\
\hline \multicolumn{7}{|l|}{ Alkanols } \\
\hline \multicolumn{7}{|l|}{ Concentration ( $/ \mathrm{g} / \mathrm{g})$} \\
\hline $\begin{array}{l}\text { unbound } \\
\text { bound }\end{array}$ & 1770 & 30 & 7410 & 12 & 10900 & 13 \\
\hline \multicolumn{7}{|l|}{$\mathrm{n}-\mathrm{C16} / \mathrm{n}-\mathrm{C} 26$ ratio } \\
\hline unbound & $>100$ & 13 & $>100$ & 1.0 & $>100$ & 0.9 \\
\hline bound & $>100$ & 12 & $>100$ & 1.4 & $>100$ & 2.0 \\
\hline \multicolumn{7}{|l|}{ Sterols } \\
\hline \multicolumn{7}{|l|}{ Concentration $(\mu \mathrm{g} / \mathrm{g})$} \\
\hline unbound & 1655 & 111 & 998 & 34 & 2090 & 68 \\
\hline bound & 37 & 16 & 148 & 8 & 719 & 11 \\
\hline \multicolumn{7}{|l|}{$\mathrm{C} 27 / 029$ ratio } \\
\hline unbound & 9.6 & 1.2 & 7.1 & 1.2 & 4.9 & 1.2 \\
\hline bound & 1.9 & 0.3 & 1.2 & 0.6 & 0.9 & 0.7 \\
\hline
\end{tabular}

In material collected in the shallower traps, concentrations of total organic carbon and of total lipid fractions generally increase with distance from land. Exceptions to the general increase are found in concentrations of bound hydrocarbons, which are highest. and of unbound sterols, which are lowest, at Station 7 above the base of the lake bottom slope.

The deep traps, positioned $1 \mathrm{~m}$ off the bottom, contain lower concentrations of total organic carbon and of total lipid class materials than do the shallower traps. Organic carbon concentrations change little between the three locations in contrast to lipid components. Hydrocarbon values progressively decrease with distance from shore and increasing water depth, but the lowest concentrations of the other three lipid classes exist in the deep trap contents of Station 7.

Table 2 gives the concentrations of organic constituents in suspended particulate matter collected in the plume at the mouth of the Grand River, in the nearshore zone of Lake Michigan, and offshore close to sediment trap Station 8 (see Fig. 1). These values are expressed in units of mass per water volume in order to compare the rclative amounts of organic material present in the three different lake environments. The amount of organic matter, measured as total organic carbon, is highest in the river plume and abour equal at both the nearshore and offshore locations, consistent with earlier results (MEYERS et al., 1981) for river mouth, nearshore, and open lake locations in Lake Michigan. Highest concentrations of extractable lipids occur in the river plume materials and accompany their higher TOC value. The nearshore and offshore particulates have substantially lower lipid concentrations than found at the river mouth location, and there appears to be an inverse relationship between unbound lipid concentrations and TOC.

Concentrations of each lipid subfraction from extracts of suspended particulate matter are consistently higher in the unbound than in the bound portions. In comparison to the sediment trap samples, the ratio of unbound to bound components of each lipid class is generally greater in these suspended matter samples. The values from the offshore stations offer the best comparison, coming from nearly the same location. For hydrocarbons, the unbound/bound ratio is 11.3 for suspended matter, 2.9 for the shallow trap sample, and 20.6 for the near-bottom trap. Corresponding values for alkanols are $11.0,5.5$, and 4.9 , and for sterols $15.0,2.9$, and 6.2 , respectively.

The results of analysis of the surficial sediment sample from Station 8 are summarized in Table 3. The ratios of unbound-to-bound materials are 1.4 for fatty acids, 4.9 for hydrocarbons, and 6.2 for alkanols, and continue the trend of decreasing ratios with greater depth seen in the sediment trap data (Table 1). Concentrations of the lipid fractions are substantially lower than those of the sediment trap materials in Table 1, perhaps as a result of dilution of organic content by the bulk mineral content of the top $10 \mathrm{~cm}$ of sediments. This effect is also evident from the TOC value of 14 $\mathrm{mg} / \mathrm{g}$ for the surficial sediment, which contrasts with the near-bottom sediment trap values of 34 to $41 \mathrm{mg} / \mathrm{g}$.

The information provided by analysis of the sediment trap contents and of the suspended sediment

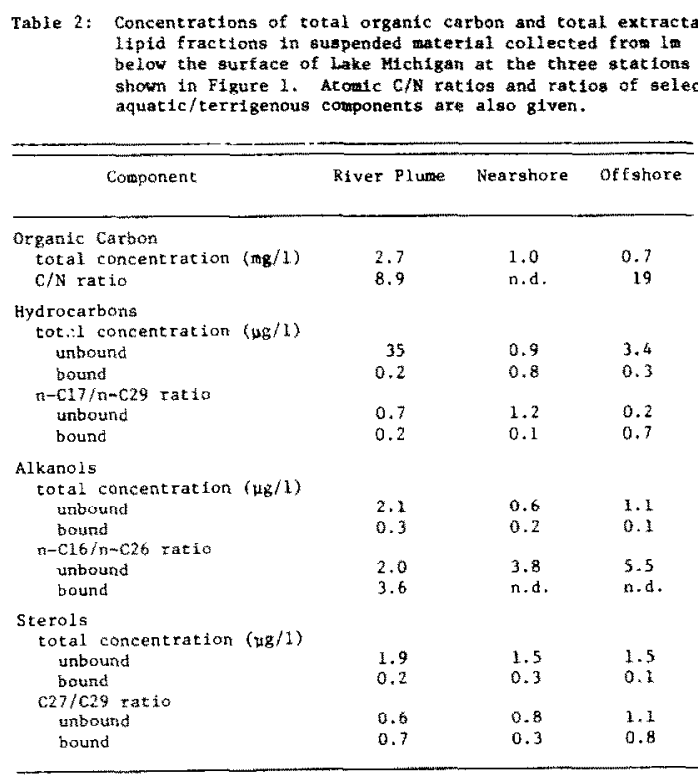

n.d., not determitned 
Table 3: Concentrations and aquatic/ cerrigenous component ratios of Ilpid fractions of surficia bottom sediment f rom Station 8 in Lake Michigan (Figure ).

\begin{tabular}{|c|c|c|}
\hline Component & iinbound & Bound \\
\hline \multicolumn{2}{|l|}{ Fatty Acids } & $=8 .:$ \\
\hline C16/c26 n-alkanoics & $\therefore 5$ & 4,5 \\
\hline \multicolumn{3}{|l|}{ Hydrocarbons } \\
\hline $\begin{array}{l}\text { Concentration ( } \mu g ; g) \\
\text { c16/C29 nulkanes }\end{array}$ & $+\frac{5}{4}$ & $\begin{array}{l}1.1 \\
a .4\end{array}$ \\
\hline \multicolumn{3}{|l|}{ Alkanols } \\
\hline $\begin{array}{l}\text { Concentration (Hg/g) } \\
\mathrm{C} 16 / \mathrm{C} 26 \text { nmalkanols }\end{array}$ & 23 & $\therefore, \cdots$ \\
\hline \multicolumn{3}{|l|}{ Sterols } \\
\hline $\begin{array}{l}\text { Concentration }(\mathrm{ig} / \mathrm{g}) \\
\text { C27/C29 sterols }\end{array}$ & $\begin{array}{c}0.3 \\
0 . ?\end{array}$ & nid \\
\hline
\end{tabular}

nd $=$ not determined

samples forms the basis for addressing four main questions concerning organic matter cycling in large lake environments:

1. What are the important sources of sedimenting organic matter in Lake Michigan?

2. What are the effects of degradative processes upon the quantity and character of organic materials sinking through the water column?

3. What are the major transport and distribution processes responsible for the organic matter patterns which are found?

4. What relationships exist between the settling or ganic matter and that which becomes incorporated within the lake bottom?

\section{Organic matter sources}

Biological origins of organic matter can often be inferred from elemental and molecular constitutions. The atomic $\mathrm{C} / \mathrm{N}$ ratio of marine plankton is about 6 (MUller, 1977), whereas this ratio in land-derived organic debris ranges between 12 and 14 (PRAHL $e t$ al., 1980). Two phytoplankton species common to Lake Michigan have $C / N$ values of 7.5 and 8.6, while a soil sample and several land plants give ratios between 16 and 45 (BOURBONNIERE, 1979). The differences between aquatic and terrigenous elemental compositions reflect the presence of nitrogen-poor cellulose and lignin in land plants and can be used as indicators of the origins of bulk organic matter. The $\mathrm{C} / \mathrm{N}$ ratios of the sediment trap materials (Table 1) are between 7 and 10 , indicating a large proportion of aquatic organic matter. The near-bottom traps appear to contain slightly greater aquatic contributions than do the shallower traps. Particulate organic matter in the plume of the Grand River (Table 2) also is predominantly of aquatic origin according to its $C / N$ ratio, but the open lake particulate material appears to be largely terrigenous.

Molecular identifications of lipid components of sediment trap contents have been used to infer sources of organic matter (CRISP et al., 1979; PRAHL and CAR PENTER, 1979; MEYERS et al., 1980; PRAHL el al. 1980: WAKEHAM $e t$ al., 1980; WAKEHAM, 1982; GAGOSIAN it al. 1982, 1983). The various lipid classes commonly used in geochemical studies and their origins are sum. marized by SIMONEIT (1978). Among the straight-chain compounds, odd-chain-length $C_{23}-C_{33} n$-alkanes and even-chain-length $\mathrm{C}_{22}-\mathrm{C}_{30} n$-alkanoic acids and $n$-alkanols imply terrigenous sources. Evidence of aquatic sources is not so easily found because many compounds present in aquatic organisms also occur in land plants, yet $\mathrm{C}_{12}-\mathrm{C}_{2 n} n$-alkanes appear to give good indications of aquatic origin. Among these hydrocarbons, $n$-heptadecane is particularly useful as an in dicator of planktonic contributions (cf. GICER $e$ al. 1980). In addition, the relative dominance of $C_{27}$ sterols in aquatic organisms and of $\mathrm{C}_{29}$ sterols in land plants can be used to distinguish sources of lipid matter in young sediments (HUANG and MEINSCHEIN, 1976. 1979; NISHIMURA and KOYAMA. 1977; LEENHEER. 1981).

As shown in Figs. 2 and 3, aquatic components dominate many of the lipid distributions found in the sediment trap samples. The relative contributions of shorter-chain and long-chain $n$-alkanoic acids and $n$. alkanols are indicated by the respective $C_{16} / C_{26}$ values in Table 1 . Land-plant $\mathrm{C}_{26}$ components are virtually absent in the shallower traps in both the unbound and bound lipid fractions. In samples from the near-bottom traps, the $C_{16} / C_{26}$ ratio of fatty acids in both fractions becomes larger as the distance from land becomes greater, but never equals the strong aquatic character found in the shallower traps. The alkanoic acid content of settling matter in Lake Michigan evidently has an aquatic origin which becomes relatively more important farther from potential terrigenous contributions and is most noticeable close to the bottom of the zone of phytoplankton production (i.e., just below the epilimnion). The $\mathrm{C}_{16} / \mathrm{C}_{26}$ n-alkanol ratios in the nearbottom traps decrease away from land, indicating a greater relative terrigenous contribution. At the same time, concentrations of alkanols decrease. The combination of these two changes suggests preferential degradation of aquatic components of the alkanol fraction.

In comparison to those of $n$-alkanoic acids and $n$ alkanols, the distributions of sterols are not so strongly dominated by aquatic components (Table 1). Unbound sterol fractions in the shallower samples have an obvious lake-derived character which decreases away from land. In the near-bottom traps, the $C_{27} / C_{29}$ sterol ratios show nearly equal amounts of aquatic and terrigenous components at all locations. The bound fractions of sterols usually contain somewhat more landderived than lake-derived materials. The general picture that emerges from these data is that sterols are synthesized by aquatic sources most actively in the nearshore zone of Lake Michigan and that lake-derived compounds are degraded in the water column faster than are land-derived sterols. 

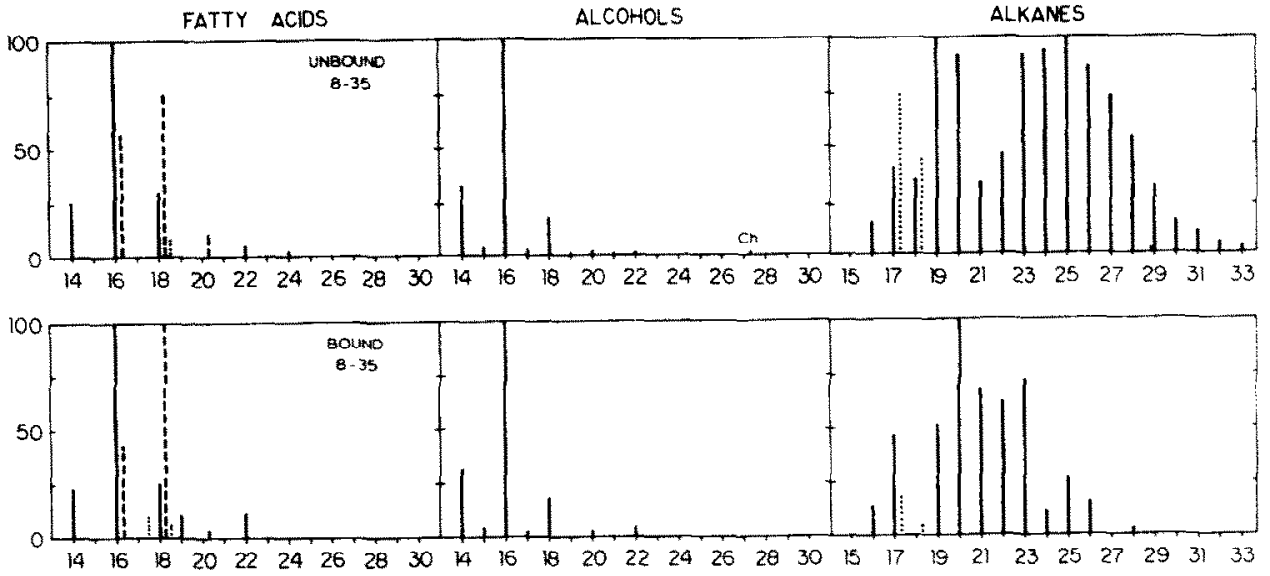

FIG. 2. Distributions of unbound and bound fractions of lipid classes extracted from settling material collected by the $35 \mathrm{~m}$ sediment trap at Station 8 . Compositions are given relative to major component $(100 \%)$. Dashed lines indicate monounsaturated $n$-alkenoic acids. Dotted lines indicate polyunsaturated $n$ alkenoic acids and pristane (after $n-\mathrm{C} 17$ ) or phytane (after $n-\mathrm{C} 18$ ). Ch represents cholesterol.

Distributions of $n$-alkanes in sediment trap material are similar to those of the acids, alkanols, and sterols in being aquatic in character, but different with respect to comparison of the epilimnion and near-bottom samples. The unbound $\mathrm{C}_{17} / \mathrm{C}_{29} n$-alkane ratios of the shallower traps indicate about equal contributions of lake and land hydrocarbons. The bound fractions have high $C_{17} / C_{29}$ ratios. These values may result from hydrolysis of intact algal cells not extracted fully by the Soxhlet procedure. Near-bottom samples have relatively high $\mathrm{C}_{17} / \mathrm{C}_{29}$ values in the unbound fractions. Unlike the other lipid classes, the unbound $n$-alkanes show a stronger aquatic character in the near-bottom trap material than in the contents of the shallower traps. These hydrocarbons evidently are subject to different processes that act upon them during settling of particulate material.

An additional factor important to the $n$-alkane distributions in the $35 \mathrm{~m}$ sediment trap contents is the possible presence of petroleum hydrocarbons. Figure 2 shows a broad distribution of unbound $n$-alkanes from $C_{21}$ to $C_{31}$ in the shallow trap from Station 8 , but a very different picture is present in Fig. 3 from the deep trap. In addition, an unresolved complex mixture (UCM) was present under the resolved hydrocarbon peaks in the $35 \mathrm{~m}$ extracts. Combination of a broad and fairly uniform n-alkane distribution and a UCM has been considered good evidence of weathered petroleum hydrocarbons in environmental samples (WAKEHAM and CARPENTER, 1976; FARRINGTON and TRIPP, 1977). Their absence in the nearbottom traps is curious and suggests selectivity in the downward transport of organic materials.

Because aquatic components are major constituents of the lipid compositions of the sediment trap contents, we expected them to be dominant in the suspended particulate material collected at a water depth of $1 \mathrm{~m}$. As Fig. 4 shows, this is not the case. Terrigenous com-
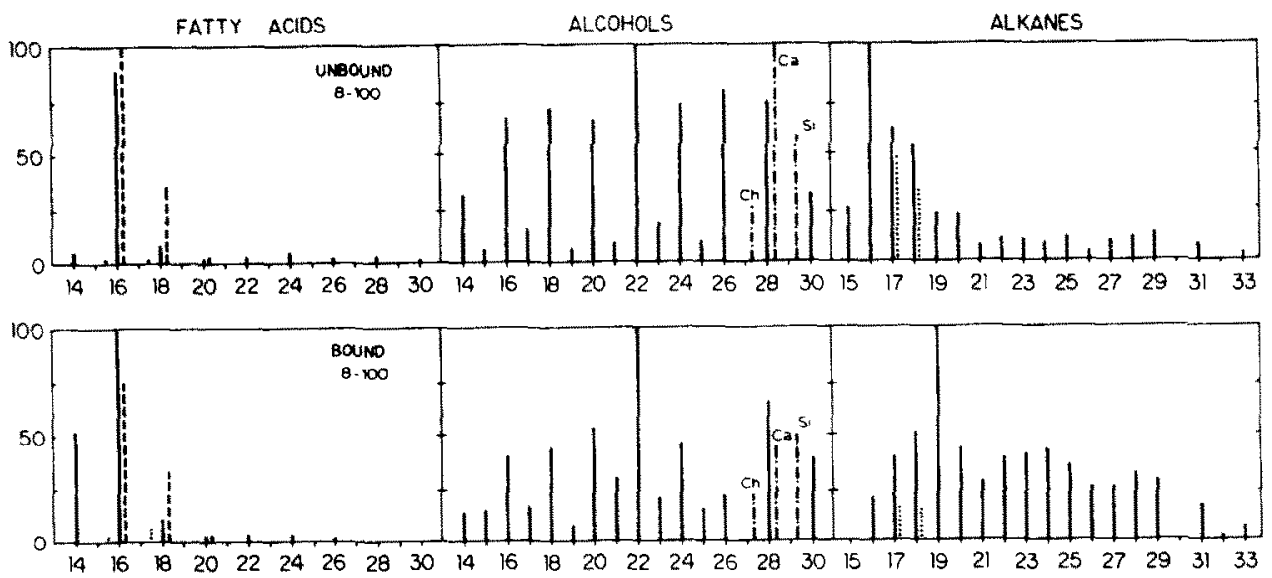

FIG. 3. Distributions of unbound and bound fractions of lipid classes extracted from settling material collected by the $100 \mathrm{~m}$ sediment trap at Station 8 . Compositions are given relative to major component $(100 \%)$. Dashed lines indicate monounsaturated $n$-alkenoic acids. Dotted lines indicate polyunsaturated $n$ alkenoic acids and pristane (near $n-\mathrm{Cl}$ ) or phytane (near $n-\mathrm{Cl}$ ). $\mathrm{Ch}$ represents cholesterol, Ca campesterol and $\mathrm{Si}$ sitosterol. 

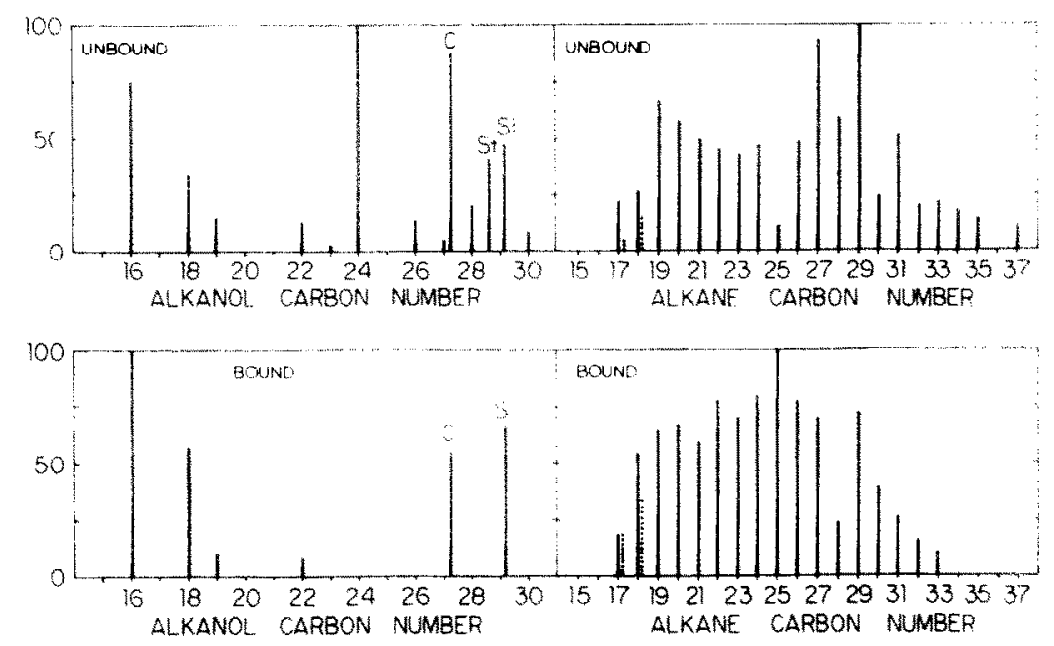

FIG. 4. Distributions of unbound and bound fractions of lipid classes extracted from particulate matte: suspended in Lake Michigan water at Station OL. Compositions are given relative to major component $(100 \%)$. Dotted lines indicate pristane (near $\mathrm{C}-17$ ) or phytane (near $\mathrm{C}-18$ ). C represents cholesterol, \& stigmasterol, and Si sitosterol.

ponents are equally or more important relative to aquatic components in both the sterol and $n$-alkane compositions. The $n$-alkanol $\mathrm{C}_{16} / \mathrm{C}_{26}$ ratios (Table 2) show somewhat more aquatic than terrigenous material, but not as much as found in shallower sediment trap contents (Table 1). In general, hydrocarbon and sterol contents indicate a slight predominance of landderived components, while $n$-alkanols show greater aquatic inputs. These source pictures are in marked contrast to the fatty acid compositions of suspended particulate matter from a depth of $1 \mathrm{~m}$ in Lake Michigan (MEYERS and OWEN, 1980) which show fatty acid distributions dominated by $C_{14}, C_{16}$, and $C_{18}$ components typical of aquatic sources and lacking significant long-chain terrigenous components. Suspended particles in the near-surface waters of Lake Michigan apparently have different mixtures of lipid sources than do the sinking particles intercepted by sediment traps.

\section{Organic matter alteration and degradation}

According to the overall organic carbon budget compiled for Lake Michigan by ANDREN and STRAND (1981), nearly all of the organic matter within the lake waters originates from aquatic primary production: only $5 \%$ of the total reaches the lake by the combination of fluvial and eolian transport. Most of this organic matter is evidently degraded within the lake, because the major removal processes, sedimentation and outflow of water, remove only $4 \%$ and $0.5 \%$, respectively, of the total input. Similar extensive organic matter degradation occurs in the upper water column of the oceans (LORENZEN et al., 1983; KNAUER and MARTIN, 1981 ; SUESS, 1980; SUESS and MÜLleR, 1980; BisHOP et al., 1978) and accompanies the sinking of detritus.

The organic carbon concentrations in Table 1 are much lower in near-bottom sediment traps than in those at $35 \mathrm{~m}$ water depth, probably as a result of dilution of settling particles with resuspended sedi. ments of lower organic matter content, because sediment traps located close to the bottom are known to intercept much resuspended material (PLATT, 1979 ; CHAMBERS and EADIE, 1981). If the concentrations of organic carbon in the nearbottom traps are expressed as percentages of their $35 \mathrm{~m}$ counterparts, a depthrelated pattern emerges. From shallowest to deepest. these values are $30 \%, 15 \%$, and $8 \%$, and suggest that organic matter destruction in Lake Michigan is linked to sinking time as also observed in marine locations (HINGa et al., 1979; SUeSS, 1980; KNAUER and MarTIN, 1981 ; LORENZEN et al., 1983). An additional possibility is that lateral transport is important for the near-bottom materials, and distance from land sources of organic matter is thus important. Comparison of the character of sediment trap organic contents can help resolve the question of dilution as opposed to destruction.

Some of the differences in lipid source character of the sediment trap contents and particulate matter noted in the previous section give evidence of a complex interaction of production, modification, and degradation of organic matter within the waters of Lake Michigan. Further evidence of the complexity of these processes is provided in Table 4, in which concentra. tions of lipid extracts are related to organic carbon contents. The highest contributions of unbound lipids to total organic matter are generally in the upper sediment traps; the lowest are in the suspended matter and in the surface sediments. Relative amounts of lipids generally are much less in the near-bottom sed. iment traps than in the upper ones, although the contributions of bound fatty acids to total organic content become larger with greater water depth.

The decreases in absolute concentrations of organic carbon and of the lipid classes shown in Table I resemble those found in sediment traps in progressively 


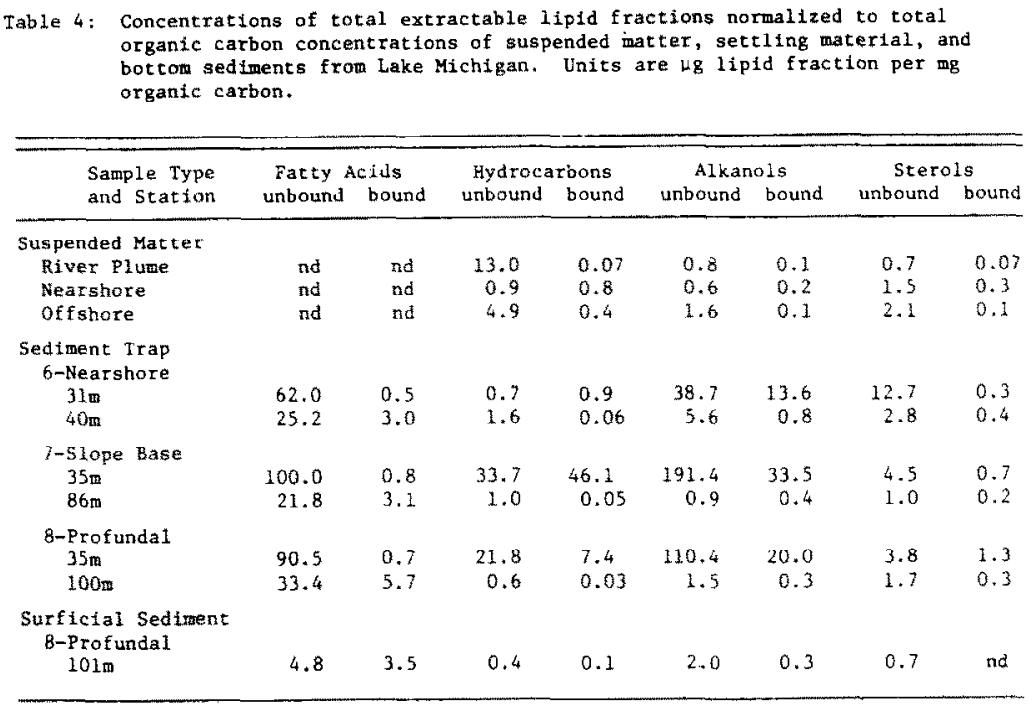

nd $=$ not determined

deeper ocean waters (SUESS, 1980; KNAUER and MARTIN, 1981; LORENZEN et al., 1983) and indicate an overall decomposition of organic matter. Decreases with depth in the amounts of lipids relative to organic contents of marine sediment traps has been interpreted by WAKEHAM et al. (1980) as evidence of preferential degradation of lipid components of sinking organic matter. Similar patterns appear in the contents of Lake Michigan traps summarized in Table 4.

The changes in lipid compositions between the 35 $\mathrm{m}$ and $100 \mathrm{~m}$ traps at Station 8 (Figs. 2 and 3) suggest greater losses of aquatic than of terrigenous components. Straight-chain alcohols are dominated by $\mathrm{C}_{16}$ in the shallower trap but by longer-chain homologs in the near-bottom location. At the same time, cholesterol is the only sterol present in significant quantity in the $35 \mathrm{~m}$ trap. This $\mathrm{C}_{27}$ sterol, plus the dominance of shorter-chain-length alkanols, indicates a strong algal character of alcohols in the shallower trap material. The contents of the deep trap are dominated by land plant $n$-alkanols and also have large contributions of land-derived $\mathrm{C}_{29}$ sterols. Similar contrasts in alcohol source character exist in Table 1 at all three sediment trap locations. Because these changes accompany decreases in total alcohol concentrations per weight of sediment as well as relative to organic carbon content, they appear to result from the overall breakdown of organic matter during settling. This process evidently impacts aquatic alcohols more than their land-derived homologs.

In contrast to the alcohol fractions, the fatty acid fractions of sediment trap contents are dominated by shorter chain autochthonous components in both 35 $\mathrm{m}$ and $100 \mathrm{~m}$ traps (Figs. 2 and 3 ). Some contributions of longer chain acids become noticeable in the nearbottom distributions, but these are not large. The presence of significant amounts of unsaturated acids (mostly palmitoleic and oleic) suggests recent biosynthesis of fatty acids, because unsaturated acids are rap- idly metabolized in sedimentary environments (RHEAD et al., 1971; CRANWELL, 1981). As concluded by MEYERS et al. (1980), the similarity of fatty acid compositions at three water depths in Lake Michigan, combined with decreases in concentrations with greater depths, suggests that microbial synthesis of fatty acids accompanies the degradation of sinking organic matter. Such continuing formation may explain why the fatty acid contributions to organic carbon in Table 4 do not decrease as much as do those of hydrocarbons, $n$ alkanols, and sterols-lipid classes which usually are more resistant to degradation than are acids ( $c$. CRANWELl, 1981; LeENHEER, 1981).

Differences exist between the ratios of pristane-toheptadecane and phytane-to-octadecane in the $35 \mathrm{~m}$ and near-bottom hydrocarbon contents of the sediment traps. Figures 2 and 3 show higher amounts of isoprenoid hydrocarbons relative to $n$-alkanes in the unbound extracts from Station 8. Microbial degradation preferentially removes straight-chain hydrocarbons (BLUMER and SASS, 1972) relative to branched hydrocarbons; hence, these differences are not due to degradation. Instead, the dominant sources of the hydrocarbon components in the shallow and deep traps may not be the same.

\section{Organic matter transport and distribution}

Organic matter can be carried to locations on the bottom of Lake Michigan by both vertical and lateral transport. HiNGA et al. (1979) discuss the vertical processes which result in accumulation of organic substances in the deep sea floor. The downward llux of particles, mostly as fecal pellets, is augmented by sinking of plant and animal debris. In addition, vertical migration of animals can transport organic matter from upper waters to deeper waters where undigested material is excreted. At and near the seafloor, organisms metabolize organic matter, thus diminishing the 
amount that survives to become incorporated into the bottom. The same set of vertical processes may operate in Lake Michigan.

Lateral transport of sediment particles is not well documented in the Great Lakes, but can be inferred from distributions of suspended particles and from patterns of sediment accumulation. In Lake Michigan. high concentrations of suspended materials are found in two depth zones-one in the region of the thermocline and another near the lake bottom (CHAMBERS and EADIE, 1981; HARRSCH and REA. 1982). Sedimentation rates in southeastern Lake Michigan are greatest near the base of shore slope (ROBBINS and EDGINGTON, 1975), rather than in the deepest basins. Comparison of sediment mass accumulation rates in near-bottom sediment traps with long-term sedimentation rates commonly shows substantially more material accumulating in the traps than in the bottoms of the Great Lakes (CHARLTON, 1975; CHAMBERS and EADIE, 1981), suggesting that much sediment resuspension occurs, which enhances opportunities for sediment lateral transport before permanent deposition. During such transport, selective settling of organic particles is possible (cf. DAvIS and BRUBAKER, 1973).

Differences in lipid compositions suggest that the organic matter contents of suspended particles in nearsurface waters, at a water depth of $35 \mathrm{~m}$, and near the water-sediment boundary are not the same. Part of the differences may be due to selective degradation, but origin and transport to the respective locations in Lake Michigan seem to be important for some of the differences in organic matter character.

Organic matter associated with suspended particles collected from a water depth of $1 \mathrm{~m}$ has a strong terrigenous lipid character in river mouth, nearshore, and open lake locations (Table 2). Because the $1 \mathrm{~m}$ sampling depth is above the zone of maximum phytoplankton growth in Lake Michigan (STADELMAN et al., 1974; TARAPCHAK, pers. commun.), aquatic components are not abundant. The unbound hydrocarbon distributions in Fig. 4 contain large contributions of the $\mathrm{C}_{27}, \mathrm{C}_{29}$, and $\mathrm{C}_{31} n$-alkanes which dominate hydrocarbon compositions of Midwest rain and snow (MEYERS and HITES, 1982). Airborne particles from land with associated land plant material may, hence, comprise an important fraction of the suspended particulate matter near the surface of Lake Michigan.

Deeper in the water, aquatic biomarker distributions dominate the character of organic matter (Table 1, Fig. 2). The $35 \mathrm{~m}$ sediment traps were positioned in the region of high concentrations of suspended material which coincides with the base of the summer thermocline (HARRSCH and REA, 1982). Because this region of decreasing water temperature with greater depth is also the boundary between less-dense epilimnion waters and denser and more viscous hypolimnion waters, an increased concentration of suspended particles is not unusual.

Hydrocarbon distributions in the $35 \mathrm{~m}$ sediment traps contain evidence of weathered petroleum, but distributions in the near-bottom traps lack these components. These hydrocarbons should be relatively resistant to further degradation. Their absence indicates that the particles with which they are associated do not sink into the deeper waters of Lake Michigan and is evidence for segregation of organic materials on the basis of density differences and selective sinking. through the water column.

\section{Relationship of organic matter in setting partales in bottom sediments}

The organic contents of sediment trap samples and of surficial sediment from Station 8 differ. Concentrations of total organic carbon and of each lipid class are lower in bottom sediments (Table 3) than in the sediment trap material (Table 1), even in the contents of the trap $1 \mathrm{~m}$ above the lake bottom in which up to $90 \%$ of the trapped material can be resuspended bottom sediment (MEYERS et al., 1980: ChaMRFRs and EADIE, 1981).

Two factors may help explain the important differences in organic matter concentrations between near-bottom traps and lake sediments. First. resuspended sediment collected by nearbottom traps may contain a greater proportion of fine-grain-sized, more easily resuspended particles than does the lake bottom. Because organic matter concentrations are commonly greater in finer-sized sediments than in coarse ones (cf. BORDOVSKIY, 1965), resuspended material would be enriched in organic constituents relative to nonsuspended, coarse fractions. Selective resuspension of fine-sized marine sediments has been suggested as a reason for trace metal enrichments in bottom nephe loid layers in the Pacific Ocean (BAKER and FEELY. 1978). Similar size-dependent effects could occur in organic components of sediments. Temporary resuspension of organic-carbon-rich, fine-sized sedimeni particles may help explain the observation that surficial sediments in lakes often have lower organic carbon concentrations than do sediments a few centimeters deeper (MATSUDA, 1978; REA et al. 1980; LEENHEER. 1981). The deeper burial may be adequate to prevent selective winnowing of small particles by water turbulence. The second factor involves destruction of organic matter at the water-sediment interface as inferred from comparisons of organic contents of sediment traps and underlying sediments (COBLER and DYMOND. 1980; PRAHL et al., 1980). Microbial metabolism of sedimented organic matter may help account for the differences in concentrations of TOC and lipid fractions observed at Station 8 in Lake Michigan.

Lipid biomarkers also differ between the sediment trap samples and the underlying sediment at Station 8. In general, the geolipid composition of surficial sediment (Table 3) has less of an aquatic character than does the content of either the $35 \mathrm{~m}$ or the $100 \mathrm{~m}$ sediment trap (Table 1). Factors affecting organic matter concentrations can also influence organic composition. For example. THOMPSON and EGLINTON 
(1978) examined lipid contents of five size fractions of sediment from an English lake. Highest concentrations of fatty acids and hydrocarbons were found associated with the smallest size fraction. Relative abundance of $C_{16}$ to $C_{20}$ n-alkanes indicative of algal origin became progressively greater in smaller-sized sediment fractions. The greater aquatic character of hydrocarbons in the near-bottom sediment trap at Station 8 $\left(\mathrm{C}_{17} / \mathrm{C}_{29}=5.3\right.$, Table 1$)$ as compared to those in underlying bottom sediments $\left(C_{17} / C_{29}=0.7\right.$, Table 3$)$ may result from selective resuspension of smaller particles. Degradation of organic matter at the benthic boundary can also affect the distribution of biomarkers. PRAHL et al. (1980) conclude from measurements of hydrocarbon fluxes in sediment traps and surface sediments of Dabob Bay, Washington, that aquatic materials degrade more rapidly at the water-sediment interface than do terrigenous components. As a result, hydrocarbon distributions in bottom sediments differ from those in settling particles in containing predominantly land-derived longchain $n$-alkanes.

While the types of organic matter in sediment traps and in the bottom of Lake Michigan differ, the character of suspended particulates in the river-plume station (Table 2) closely resembles that of the surficial sediments (Table 3). Although it is tempting to suggest that the suspended materials brought to the lake by the river flow travel to deep parts of the lake as some sort of near-bottom density flow, CHAMBERS and EADIE (1981) find no evidence of an important fluvial contribution to the near-bottom nepheloid layer in Lake Michigan. The similarities in biomarkers of the rivermouth and surficial sediment samples, however, do indicate the importance of terrigenous contributions to surficial sediments.

\section{CONCLUSIONS}

Differences in the amount and types of geolipids present in particulate matter found at various depths and locations in Lake Michigan suggest a complex interplay of organic matter production, alteration, and destruction which accompanies the settling of sediment particles through the water. Some of the elements of this interplay are generalized as:

1. Suspended particulates in the top meter of the open-lake waters contain a major component of terrigenous lipid matter brought to these locations, presumably by eolian transport.

2. Settling particles in the metalimnion contain predominantly aquatic lipid matter.

3. Organic matter associated with sinking particles undergoes substantial degradation during sedimentation in Lake Michigan. Aquatic lipid components are selectively destroyed relative to the terrigenous components of this organic material.

4. Petroleum hydrocarbons are associated with particles collected in sediment traps in the metalimnion but not with shallower or deeper particles, evidently as a result of density segregation of settling particles.
5. Resuspension of surficial sediments causes selective removal of finer fractions from the lake bottom and corresponding enrichment of bottom nepheloid laycrs with thesc sediment size classes. Because aquatic lipid matter is preferentially associated with the fine fractions, nepheloid particulate matter has an aquatic biomarker character, whereas bottom sediments have a terrigenous character.

Acknowledgements-We thank R. A. Bourbonniere for his helpful comments to improve our manuscript and $O$. E. Kawka, K. D. Flessland, A. H. Wasek, and P. A. Pulver for their assistance in laboratory and field work.

This study was supported in part by grant number EAR7822432 from the NSF Earth Sciences Division. Acknowledgement is made to the donors of the Petroleum Research Fund administered by the American Chemical Society for partial support. Great Lakes Environmental Research Laboratory Contribution 391.

\section{REFERENCES}

ANDREN A. W. and STRAND J. W. (1981) Atmospheric deposition of particulate organic carbon and polyaromatic hydrocarbons to Lake Michigan. In Atmospheric Pollutants in Natural Waters (ed. S. J. EISENREICH), pp. 459-479. Ann Arbor Science.

BAKER E. T. and FEeLY R. A. (1978) Chemistry of oceanic particulate matter and sediments: Implications for bottom sediment resuspension. Science 200, 533-535.

BiSHOP J. K. B., KeTTEN D. R. and EDMOND J. M. (1978) The chemistry, biology and vertical flux of particulate matter from the upper $400 \mathrm{~m}$ of the Cape Basin in the southeast Atlantic Ocean. Deep-Sea Res. 25, 1121-1161.

Blumer M. and SASS J. (1972) Oil pollution: Persistence and degradation of spilled fuel oil. Science 176, 1120 1122.

BORDOVSKIY O. K. (1965) Accumulation of organic matter in bottom sediments. Mar. Geol. 3, 33-82.

BOURBONNIERE R. A. (1979) Geochemistry of humic matter in Holocene Great Lake sediments. PhD Thesis, Univ. Michigan, $373 \mathrm{p}$.

Chambers R. L. and EAdie B. J. (1981) Nepheloid and suspended particulate matter in south-eastern Lake Michigan. Sedimentology 28, 439-447.

CHARLTON M. N. (1975) Sedimentation: Measurements in experimental enclosures. Verh. Int. Ver. Theor. Angew. Limnol. 19, 267-272

COBLER R. and DYMOND J. (1980) Sediment trap experiment on the Galápagos spreading center, equatorial Pacific. Science 209, 801-803.

CRANWELL P. A. (1981) Diagenesis of free and bound lipids in terrestrial detritus deposited in a lacustrine sediment. Org. Geochem. 3, 79-89.

CRISP P. T., BRENNER S., VENKATESAN M. I., RuTh E. and KAPLAN I. R. (1979) Organic geochemical characterization of sediment-trap particulates from San Nicolas, Santa Barbara, Santa Monica and San Pedro Basins, California. Geochim. Cosmochim. Acta 43, 1791-1801.

DAVIS M. B. and BRUBAKER L. B. (1973) Differential sedimentation of pollen grains in lakes. Limnol. Oceanogr. 18. 635-646.

DEAN W. E. (1981) Carbonate minerals and organic matter in sediments of modern north temperate hard-water lakes. SEPM Spec. Pub. 31, 213-231.

FARRINGTON J. W. and TRIPP B. W. (1977) Hydrocarbons in western North Atlantic surface sediments. Geochim. Cosmochim. Acta 41, 1627-1641.

Gagosian R. B. (1976) A detailed vertical profile of sterols in the Sargasso Sea. Limnol. Oceanogr. 21, 702-710.

Gagosian R. B.. SMith S. O. and Nigrelli G. E. (1982) 
Vertical transport of steroid alcohols and ketones measured in a sediment trap experiment in the equatorial Atlantic Ocean. Geochim. Cosmochim. Acta 46, 1163-1172.

Gagosian R. B., NigRELLI G. E. and VolkMaN J. K. (1983) Vertical transport and transformation of biogenic organic compounds from a sediment trap experiment off the coast of Peru. In Coastal Upwelling: Its Sediment Record (eds. E. SUESS and J. THIEDE). Plenum Press (in press).

Giger W., SCHAFFNer C. and WaKeHAM S. G. (1980) Aliphatic and olefinic hydrocarbons in recent sediments of Greifensee, Switzerland. Geochim. Cosmochim. Acta 44, 119-129.

Harrsch E. C. and ReA D. K. (1982) Composition and distribution of suspended sediments in Lake Michigan dur. ing summer stratification. Environ. Geol. 4, 87-98.

HiNGa K. R., Sieburth J. MCN. and HEATH G. R. (1979) The supply and use of organic material at the deep-sea floor. J. Mar Res. 37, 557-579.

Huang W.-Y. and MeInschein W. G. (1976) Sterols as source indicators of organic materials in sediments. Getchim. Cosmochim. Acta 40, 323-330.

HUANG W.-Y. and MEINSChEIN W. G. (1979) Sterols as ecological indicators. Geochim. Cosmochim. Acta 43, 739 745 .

KNAUER G. A. and MARTIN J. H. (1981) Primary production and carbon-nitrogen fluxes in the upper $1,500 \mathrm{~m}$ of the northeast Pacific. Limnol. Oceanogr. 26, 181-186.

LEENHEER M. J. (1981) Use of lipids as indicators of diagenetic and source-related changes in Holocene sediments. PhD Thesis, Univ. Michigan, $246 \mathrm{p}$.

LORENZEN C. J.. WelshmeYer N. A. and Copping A. E. (1983) Particulate organic carbon flux in the subarctic Pa. cific. Deep-Sea Res. 30, 639-643.

MATSUOA H. (1978) Early diagenesis of fatty acids in lacustrine sediments-III. Changes in fatty acid composition in the sediments from a brackish lake. Geochim Cosmochim Acta 42, 1027-1034.

MEYERS P. A. and OWEN R. M. (1980) Sources of fally acids in Lake Michigan surface microlayers and subsurface waters. Grophys. Res. Lett. 7, 885-888.

Mejers P. A. and Hites R. A. (1982) Extractable organic compounds in Midwest rain and snow. Atmos Environ 16, $2169-2175$.

MEYERS P. A., EDWARDS S. J. and EADIE B. J. (1980) Fatty acid and hydrocarbon content of settling sediments in Lake Michigan. J. Great Lakes Res. 6, 331-337.

MEYers P. A. OWEN R. M. and MACKIN J. E. (1981) Organic matter and heavy metal concentrations in the particulate phase of Lake Michigan surface microlayers. In Almospheri, Pollutants in Natural Waters (ed. S. J. EISENREICH), pp. 129-141. Ann Arbor Science.

Müller P. J. (1977) C/N ratios in Pacific deep-sea sediments: Effect of inorganic ammonium and organic nitrogen com. pounds sorbed by clays. Ganhim Casmochim Acto 41 . $765-776$.
Nishimura M. and Koyama T. (1977) The occurrence of stanols in various living organisms and the bethavior of sterols in contemporary sediments. Geochim Cusmochim Acta 41, 379-385

PLATT H. M. (1979) Sedimentation and the distribution of organic matter in a sub-Antarctic manine bay. Ewhar. Coast. Mar. Sci. 9, 51-53.

Prahl F. G. and Carpenter R. (1979) The role of $200-$ plankton fecal pellets in the sedimentation of polycyclic aromatic hydrocarbons in Dabob Bay. Washington. Ge? chim. Cosmochim. Acta 43, 1959-1972.

PRaHL F. G., BenNetT J. T. and CaRpenter R. (1980) The early diagenesis of aliphatic hydrocarbons and organic matter in sedimentary particulates from Dabob Bay. Washington. Geochim. Cosmochim. Acta 44, 1967-1976.

REA D. K.. BOURBONNIERE R. A. and MEYERS P. A. (1980) Southern Lake Michigan sediments: Changes in accu. mulation rate. mineralogy and organic content. $j$. Great Lakes Res. 6, 321-330.

RHEAD M. M. EgLinton G.. DRAHAN G. H. and ENGLAve P.J. (1971) Conversion of oleic acid to saturated fatty acids in Severn Estuary sediments. Nature 232, 327-330.

ROBbiNs J. A. and EDGINGTON D. N. (1975) Determination of recent sedimentation rates in Lake Michigan using $\mathrm{Pb}$ 210 and $\mathrm{Cs}-137$, Geochim. Cosmochim Acta 39, 285-304.

SIMONEIT B. R. T. (1978) The organic chemistry of manine sediments. In Chemical Oceanography Iol. 7 teds. J. P. Riley and R. Chester), pp. 233-311. Academic Press.

STADELMANN P. MOORE J. E. and PICKeTt E. (1974) Priman production in relation to temperature structure, biomass concentration, and light conditions at an inshore and of shore station in Lake Ontario. J Fish. Res Boord Can. 31, 1215-1232.

SUESS E. (1980) Particulate organic carbon fux in the oceanssurface productivity and oxygen utilization. Naturt 288 , $260-263$.

SUESS E. and MÜLlER P. J. (1980) Productivity. sedimentation rate and sedimentary organic matter in the oceans 11 Elemental fractionation. Coll. Intert. CNRS 293.17-26.

THOMPSON $S$, and EGLINTON $G$. (1978) The fractomaton of a Recent sediment for organic geochemical analysis. Goohim Cosmochim. Acta 42.199-207

W AKEHAM S. G. (1982) Organic matter from a sediment trap experiment in the equatorial Nonh Atlantic: wax esters. steryl esters, triacyglycerols, and alkyldiacylglycerols. int $^{2}$ chim Cosmochim. Acla 46, 2239-2257.

WAKEHAM S. G. and CARPENTEK R. (1976) Aliphatic hy drocarbons in sediments of Lake Washington. Limnol Occanogr, 21, 711-723.

Wakeham S. G.. Farkington J. W.. Gagosian R. B. Lhe C., De BaAR H., Nigrelli G. E.. TRipp B. W. SMith S. O. and FREW N. M. (1980) Organic matter fluxes from sediment traps in the equatorial Allantic Ocean. Natur? 286. $798-800$ 